\title{
Social Experiences of Muslim Americans Regarding the Intolerance Displayed by Non-Muslims
}

\author{
Munder Abderrazzaq, $\mathrm{PhD}$ \\ Walden University, Minneapolis, Minnesota, United States \\ (iD) https://orcid.org/0000-0002-9933-5315
}

Contact:DrMunderA@gmail.com

\begin{abstract}
Non-Muslims in the United States have openly expressed their opposition regarding Muslim Americans, which has led to the racial profiling and unequal treatment of Muslim Americans. Literature regarding the intolerance displayed by majority members indicates a need for further research that explores the point of view of minorities in the United States. Intolerance is defined as the refusal and unwillingness to respect or tolerate persons of a different social group or members of minority groups who hold beliefs contrary to one's own. The intolerance displayed among members of different religious and cultural backgrounds can limit the ability to discover new information needed in promoting positive social change among Muslims and nonMuslims in the United States. Semistructured interviews were used to explore the social experiences of Muslim Americans of Palestinian descent in Cleveland, Ohio, regarding prejudice and discrimination displayed by non-Muslims. The theory of planned behavior and impression management theory were used as the framework for this study. Convenience and purposeful sampling were used to recruit the 10 participants chosen for this study. Template analysis, Giorgio's psychological phenomenological method, and coding were used to analyze the data obtained from this study. Participants revealed experiencing prejudice and discrimination "everywhere" and "anywhere," including verbal attacks and emotional distress. Participants also described the intolerance among Muslims and non-Muslims as "good and bad" or "it depends." Information from this study can help in the development of social strategies that can be used to improve the interactions among Muslims and non-Muslims in United States.
\end{abstract}

Keywords: culture, discrimination, intolerance, Muslim Americans, non-Muslims, prejudice, and social experiences

Date Submitted: March 15, 2021 | Date Published: November 9, 2021

Recommended Citation

Abderrazzaq, M. (2021). Social experiences of Muslim Americans regarding the intolerance displayed by non-Muslims. Journal of Social, Behavioral, and Health Sciences, 15(1), 278-292. https://doi.org/10.5590/JSBHS.2021.15.1.19

\section{Introduction}

Since the September 11, 2001, terrorist attacks in New York City, Muslim Americans in the United States have experienced stigmatization, stereotyping, prejudice, and discrimination (Amer \& Bagasra, 2013; Khan, 2014; Lamont \& Collet, 2013; McDowell-Smith, 2013; Mohibullah \& Kramer, 2016; Rosenthal et al., 2015; Zainiddinov, 2016), which has also been motivated by more recent events such as the April 13, 2013, Boston 
Marathon terrorist attacks and other random acts of terrorism throughout the United States. An estimated 3.45 million Muslims lived in the United States in 2017, a number which is expected to more than double to 8.1 million by 2050 (Pew Research Center, 2017, as cited in Mohamed, 2018). The participants chosen for this study were Muslim Americans of Palestinian decent who reside in Cleveland, Ohio. According to Zainiddinov (2016), compared to other major religious and racial groups in the United States, Muslim Americans are more likely to experience discrimination. Muslim Americans experience verbal abuse, physical threats, defacement and vandalism of mosques, harassment on college campuses, and racial profiling in communities and airports based on their ethnicity, color, and religion (Samari, 2016; Zainiddinov, 2016).

Intolerance is defined as the refusal or unwillingness to tolerate members of different social groups or minority groups who hold different opinions or beliefs (Dictionary.com, n.d.). Discrimination displayed by non-Muslims towards Muslims and those perceived as Muslim has led to the profiling and denial of employment of Muslim Americans in the United States (Samari, 2016). The term non-Muslim is defined as a person who does not identify as Muslim or hold any Islamic religious beliefs. Social experiences such as these can have negative social and personal consequences for Muslim Americans. Social experiences are defined as events that individuals have actually lived through and experienced (American Psychological Association, n.d.).

In a 2017 survey of Muslims in the United States, 75\% of Muslim American adults stated that there is "a lot" of discrimination and 50\% stated increased difficulty of identifying as a Muslim in the United States (Pew Research Center, 2017, as cited in Kishi, 2017). Muslim Americans are treated as unworthy of the universal protections given to American citizens by non-Muslims, which is the result of the belief that they pose a threat to American society (Selod, 2014). Recent literature has shown that Muslim Americans are presented by American media as violent terrorists, which has influenced negative attitudes by non-Muslims towards Muslim Americans (Saleem et al., 2017). These representations of Muslim Americans by media outlets have increased the concerns by non-Muslims regarding the integration and migration of Muslims in the United States (McDowell-Smith, 2013). The intolerance displayed by non-Muslims towards Muslim Americans can be observed throughout American society, with newspapers, movies, cable news, television, video games, and media outlets associating Muslims with violence and terrorism (Saleem et al., 2017).

Muslim women who wear a hijab are often portrayed by American media as distressed and oppressed, needing to be liberated from a male-dominant culture (Mohibullah \& Kramer, 2016). The hijab is a traditional headscarf worn by Muslim women to convey their cultural and religious beliefs (Ali et al., 2015; Mohibullah \& Kramer, 2016). Muslim women in the United States who wear the hijab have reported being targets of physical and verbal assaults by non-Muslims in public, which is the result of the hijab being portrayed as a cultural threat and in opposition to Western values and ideals of feminism (Selod, 2014). Muslim women in the United States who wear the hijab increasingly experience hostility in public and are targets of assaults, as the result of being perceived as submissive and not physically intimidating by non-Muslims. These types of social experiences have led to prejudice and discrimination against Muslim women and motivated some to remove their hijab due to negative portrayals and stereotypes (Ali et al., 2015).

Muslim Americans have experienced discrimination in every aspect of their lives, which has been reported in workplaces, prisons, and leisure settings (Zainiddinov, 2016). Threats related to negative stigmas have motivated some Muslim Americans to conceal or disidentify with their group identity (Khan, 2014). According to Selod (2014), Muslim men in the United States have reported being questioned by non-Muslims regarding their religious values in social gatherings, workplaces, and other private settings. Many Muslim men have reported avoiding situations where religion and politics are discussed, fearing they will be interrogated regarding their loyalty and values, as well as being perceived as anti-American. In a 2015 poll conducted after September 11, many non-Muslims in the United States (60\%) associated negative terms such as radical, terrorism, violence, war, and fanatic when describing Muslims (as cited by Samari, 2016). 
The lived experiences of Muslim Americans have mostly been ignored in recent psychological literature. Yet, there is a need for psychologists to better understand the lived experiences of Muslims Americans to help improve the well-being of these individuals (Amer \& Bagasra, 2013). Such knowledge would also help those involved in civic engagement and other social service professions who attempt to improve the lives of Muslim Americans. Social situations involving surveillance, hate crimes, and institutional discrimination demonstrate a need to understand the social experiences of Muslim Americans (Amer \& Bagasra, 2013). Recently recommended interventions regarding prejudice and discrimination have emphasized changing how individuals of different cultural and religious beliefs interact, by creating social/economic conditions and programs that reduce discrimination, inequities, and increase civic engagement (Ellis \& Abdi, 2017). According to Goffman's (1959) impression management theory, people attempt to control the impression others form of them as a way of avoiding undesirable outcomes, which is motivated by their experiences and the audience that is present (Leary \& Kowalski, 1990). As emphasized by Goffman, self-presentation is used by individuals as a way of attempting to control and define their social encounters with others (as cited in Leary \& Kowalski, 1990).

Another theory that was used as the theoretical framework for this study is Ajzen's (1991) theory of planned behavior, which states that the intentions of individuals are motivated by their perception regarding how they are perceived by others and their individual experiences (Leary \& Kowalski, 1990). According to Ajzen's theory of planned behavior, intentions represent the motivational factors that influence behavior and are motivated by the person's beliefs about the attitudes and expectations of others, as well as the degree of control regarding the behavior that is performed. Exploring the social experiences of Muslim Americans can help to identify the consequences and functions regarding the tolerance displayed by non-Muslims (Ellis \& Abdi, 2017). The research question for this study was: What are Palestinian Muslim Americans' social experiences regarding the intolerance displayed by non-Muslims?

As noted in recent literature, there is a need to further explore the point of view of minorities regarding the intolerance displayed by majority members (Simon et al., 2018), a gap that was addressed in this research. Conducting research that explores the social experiences of Muslim Americans can allow new information to be discovered regarding the intolerance displayed by non-Muslims in the United States. According to the American Psychological Association (2003), research that identifies and describes the diverse ethnic, cultural, and religious orientations in the Unites States is needed to understand the environmental factors that influence the behavior of individuals and groups. The possible discovery of new information from this research can be used to address existing social problems regarding the intolerance displayed by non-Muslims that have not been explored in previous research. Such knowledge can be used in developing social strategies to promote positive social change among Muslims and non-Muslims in the United States.

\section{Impression Management Theory}

Impression management theory was applied to this study to better understand how the lived experiences of the participants influenced their behavior towards non-Muslims. According to Goffman's (1959) impression of management theory, the social behavior of individuals is dependent on the audience that is present (as cited in Tseëlon, 1992). People constantly change the behavior they display to others as a way of maintaining and supporting their desired self-concept and social identity, while attempting to control the impressions others form of them (Leary \& Kowalski, 1990). A tenet of Goffman's theory is that the behavior displayed by individuals is motivated by factors such as role constraints, values of the audience, desired social identity, and discrepancies between desired and current social identity (as cited in Leary \& Kowalski, 1990). As a result, individuals tend to present themselves in ways others will approve, which allows them to avoid undesired outcomes involving situations and events (Paliszkiewicz \& Madra-Sawicka, 2016). 


\section{Theory of Planned Behavior}

The theory of planned behavior was applied to this study to better understand how the lived experiences of the participants influences their intentions and decision-making towards non-Muslims. Ajzen's (1991) theory of planned behavior states that behavior is guided and motivated by the normative expectations of others, factors that are present that may further or hinder the behavior performed, and the person's belief regarding behavioral outcomes (see also Ajzen \& Fishbein, 2000). The intentions of individuals are considered motivational factors that influence behavior and the degree of effort planned towards the behavior displayed (Ajzen, 1991). Intentions and decision-making are believed to be influenced by subjective norms regarding the reactions and interpretations of others, the individual's ability regarding the behavior performed, and beliefs of the behavior performed (Ajzen, 1991).

\section{Method}

To explore Palestinian Muslim Americans' social experiences regarding the intolerance displayed by nonMuslims, I chose a qualitative research method, which allowed me to study and obtain a holistic picture of the phenomenon in its natural setting (see Creswell \& Creswell, 2018; Thompson, 2018). Other qualitative designs (e.g., ethnography or case study) could have been used; however, a phenomenological design was chosen for its focus on understanding how individuals interpret their personal and social world through firsthand, detailed descriptions of events, specific experiences, and views held by the individual (Alase, 2017; Matua \& Van Der Wal, 2015). Researchers of previous studies involving Muslim Americans have reported difficulties in recruiting enough participants, citing that some Muslims avoided participating because they feared or were suspicious that "the researcher was working for the government or would manipulate the data to cause harm to the community" (Amer \& Bagasra, 2013, p. 139). I was of the same origin of descent as the participants and socially identify as Palestinian Muslim American, which may have helped mitigate possible issues of distrust among the participants regarding the purpose of the study.

\section{Participants}

After obtaining approval from the university's Institutional Review Board, I recruited participants using flyers posted at Middle Eastern businesses located in Cleveland, Ohio, with a predominantly Middle Eastern clientele. Participation was open to all adult Palestinian Muslim Americans from Cleveland, Ohio. Interviews were conducted until saturation was reached at 10 participants, who met all the eligibility criteria to participate in the study. A representative sample consisting of five female and five male Palestinian Muslim American adults from Cleveland, Ohio, was recruited, selected, and interviewed. To be selected, participants were required to (a) be 18 years old or older, (b) be of Palestinian descent, (c) identify as a Muslim, and (d) be from Cleveland, Ohio. The names of all participants in this study were changed to maintain participant confidentiality. The participants' demographics are indicated in Table 1. 
Abderrazzaq, 2021

Table 1. Participant Demographics

\begin{tabular}{llll}
\hline \multicolumn{1}{c}{$\begin{array}{c}\text { Participant } \\
\text { identifier }\end{array}$} & Gender & Age & \multicolumn{1}{c}{ Occupation } \\
\hline Sara & Female & 40 & Childcare worker and college student \\
Mona & Female & 29 & Stay-at-home mom \\
Fatima & Female & 22 & College student \\
Miriam & Female & 36 & Stay-at-home mom \\
Dena & Female & 31 & Stay-at-home mom \\
Ahmad & Male & 27 & Business owner \\
Hasan & Male & 29 & Barber \\
Kamal & Male & 38 & Undisclosed or unknown \\
Abed & Male & 18 & Undisclosed or unknown \\
Musa & Male & 24 & Undisclosed or unknown \\
\hline
\end{tabular}

\section{Procedure}

Prior to posting the flyers at businesses, I obtained consent from partner organizations, such as Middle Eastern grocery stores, restaurants, and barbershops. After obtaining consent the flyers were posted in the businesses. Individuals interested in participating responded to the flyers which included information on (a) the need for participants for a research study on the experiences of Palestinian Muslim Americans in Cleveland, Ohio, (b) the benefits and possible contributions of the study, and (c) an invitation for those interested in participating to call me for more information. The participants were recruited and selected using purposeful criterion sampling, information power, and data saturation. Therefore, individuals who called and indicated their interest in participating were screened to determine their eligibility to participate. After the eligibility prescreening process, selected participants were contacted and invited to meet me in a private conference room at a public library in Cleveland to review and sign the consent form. Prior to signing the consent form, participants were provided details regarding the study such as its purpose, potential contributions and benefits, the voluntary nature of their participation, as well as the procedures of ensuring confidentiality. I also informed participants that the interviews might take 30 minutes to an hour to complete, to ensure that they had enough time to comfortably answer the interview questions. Semistructured, face-toface interviews were conducted using interview questions (see Appendix A) I developed, which were reviewed and validated by a content expert.

\section{Analysis}

With permission obtained, I used an audio-recording device and hand-written notes to record participants' responses to ensure their accuracy. On average, the interviews lasted approximately 12 minutes, depending on the participants' responses. The audio recordings were transcribed using Microsoft Word, and the participants were asked to review the transcripts of their responses for accuracy (member checking). Also, epoché or bracketing was used to avoid or manage the influence of my perspectives. Template analysis and Giorgi's principles of psychological phenomenological method were used to analyze the data, which allowed for its extensive review.

I used Giorgi's method to interpret the data. This method is consistent with the phenomenological design, which focuses on how the individual understands and interprets their social world (Giorgi, 2012; Giorgi et al., 2017; Jackson et al., 2018). Template analysis was also used for hierarchical coding, allowing for the coding and identification of emergent themes and significant meanings during data analysis using Giorgi's method (Brooks et al., 2015; Terry et al., 2017). Using Microsoft Excel, I created tables containing the transcribed and 
member-checked raw data, which I used to review, identify, and code for emergent themes and significant meanings. Two tables (one for female participants and one for male participants) were divided into four columns; the first column was for participant identifiers. The second column included the interview questions, the third column contained participant responses to the interview questions (see Appendix A for a list of interview questions), and the fourth column was left blank to list the codes and emerging themes.

In accordance with Giorgi's psychological phenomenological method, I read the raw data as a whole to help gain a holistic understanding of the responses. The data were reviewed again to identify and highlight significant descriptions and meanings, which were categorized into meaningful units. Significant phrases, words, emerging patterns, and meaningful statements from each participant's responses were recorded and categorized as codes, especially those that were repeated by other participants. Finally, the meaningful units were reviewed to merge relevant similarities, helping to identify thematic categories and subthemes. Repeated and similar code words and phrases in responses were highlighted to identify themes and subthemes to discover the underlying meanings, trends, or similarities and differences in participants' social experiences, leading to the development of the themes and subthemes as well as establishing the trustworthiness of the interpretations of the data.

\section{Results}

I developed the interview questions to address the research question for the study, as well as to gain rich, thick, and full descriptions of the participants' social experiences regarding the intolerance displayed by nonMuslims. Several themes and subthemes emerged from the data which provided meanings and explanations of the social experiences of Palestinian Muslim Americans regarding the intolerance displayed by nonMuslims. The themes that emerged during the analysis were the result of similar lived experiences described by the participants regarding the intolerance displayed by non-Muslims. The lived experiences consisted of being verbally attacked, being treated or looked at differently, experiencing or observing prejudice and discrimination "everywhere" and "anywhere," experiencing emotional distress, and avoiding or ignoring nonMuslims. Participant responses indicated that the tolerance among Muslims and non-Muslims is "good and bad" or "it depends"; responses also highlighted the concept of "us vs. them" or "we vs. they." The subthemes that emerged from the themes were based on the similarities in specific characteristics within the themes such as the hijab, the participant's name, speaking Arabic in public or identifying as Arab, and the participants naming specific locations where they experienced or observed the intolerance displayed by non-Muslims. The following sections will provide an overview of the participants' social experiences with non-Muslims.

\section{Theme 1: Verbal Attacks}

Five participants reported experiencing verbal attacks from non-Muslims, and three mentioned being told to "go back to your country." Mona, for example, recalled an incident at the grocery store where a woman told her mother, "go back to your country, you don’t deserve to be here." Similarly, Dena mentioned incidences she experienced of being told to go back to her country saying, "every time I go to places, I do get a lot of hate, they tell me to go back to my country or stuff like that." She also talked about when she was a 15-year-old, hijabwearing girl on her way home from school, "a man began cussing me out and throwing stuff at me, telling me to go back to my country." Also, Miriam spoke about an incident with another parent at her child's swimming class describing, "[she said], 'you Arabs, you Arabs are animals you don't know how to take care of your kids. Your kind, your kind, you're garbage. Get out of here, go back to where you came from.”

The other participants discussed experiencing other forms of verbal attacks from non-Muslims. For example, when Ahmad was younger, he experienced verbal attacks for being proud of being a Muslim and where he was from, revealing, "I've heard every joke you can think of. I've been teased about it." Other participants revealed experiencing verbal attacks because they spoke Arabic. For example, Miriam was in a grocery store aisle talking on the phone when a woman walked up to her and said, "You're in America, speak English." Likewise, 
Sara remembered the cab driver saying, "Oh so you're one of them. You guys are the ones that are blowing up things" after asking her what language she spoke when she was the phone.

\section{Theme 2: Treated or Looked at Differently}

Of the 10 participants in the study, nine provided detailed accounts of observing or experiencing being treated or looked at differently because of their appearance, name, and/or ethnicity. Five out of the nine personally experienced being treated or looked at differently. Kamal, for instance, said "They look at you differently, they talk to you differently, and they basically get scared of you, they think you're gonna do something, it seems like you're from outer space." He also revealed being treated differently by non-Muslims because of his name:

They look at me weird, they treat me differently, they act differently because of my first name and my last name. It's not even my looks, basically my name. Once they see that I get treated differently, they act differently, they treat you differently overall, just different completely.

Similarly, Abed talked about an incident at a local café saying, "they didn't wanna serve me. They told me because of my name, because I was Arab." He also mentioned another incident: "I went to a store and just the fact that I was Arabic and Muslim the cashier told me that 'I don't serve your kind of people." Hasan also expressed experiencing being looked at differently stating, "Anytime I pray I feel that a lot of people look at me differently." He went on further to say he felt "hatred, unwanted, people just look at you differently."

Musa described another example of experiencing being looked at or treated differently by non-Muslims stating,

Going through the airport they see you speaking Arabic or going through the TSA [and] you're with family that's wearing the hijab, they tend to look at you in scrutiny and search you a lot longer. Basically, they search you a lot longer and start asking you more questions that they would ask other people.

Finally, although she never personally experienced being treated or looked at differently, Fatima observed "the worst of the worst in other people, they [Muslim women] get discriminated just from wearing the headscarf and it's truly sickening." The following subthemes emerged during the analysis of the participants' discussions about experiencing or observing being treated or looked at differently based on the hijab, their names, and speaking Arabic in public or identifying as Arab.

\section{Subtheme 1: The Hijab}

Six of the nine participants specifically mentioned observing or experiencing being treated or looked at differently because of the hijab. For instance, Mona stated, "I wear the hijab, anytime I would go anywhere a lot of people would look at us very differently and we would get a lot of negative feedbacks." She also discussed an incident that occurred with her hijab-wearing mother at the grocery store in which "a lady literally got in her face and was like, 'go back to your country, you don't deserve to be here' and yanked my mother's hijab off of her." She also expressed, "this is normal; because of my hijab, you wanna automatically assume I don't speak English or I'm a foreigner.” Dena also shared her experience when she was 15 years old and wore the hijab saying, "I was walking home from school, I used to wear the hijab. A man flips me off and he was cussing me out and throwing stuff at me, telling me to go back to my country."

Although Fatima did not personally experience it herself, she discussed observing hijab-wearing women "get discriminated just from wearing the headscarf and it's truly sickening." Other participants also mentioned observing hijab-wearing women being treated or looked at differently. For example, Hasan described similar incidences he observed saying, "our Muslim sisters [who have] the hijab on, there's a lot of people that say smart remarks. There's a lot of people that asks stupid questions about it, why they wear it." Similarly, Musa revealed 
his observations and experiences at airports, "going through the airport, you're with family that's wearing the hijab, they tend to look at you in scrutiny and search you a lot longer."

\section{Subtheme 2: Participant's Name}

Of the nine participants, two specifically mentioned experiencing being treated or looked at differently because of their name. Kamal stated, "It's not even my looks, basically my name. Once they see that I get treated differently, they act differently, they treat you differently overall just different completely." Abed also discussed an incident at a local café recalling, "they didn't wanna serve me. They told me because of my name, because I'm Arab."

\section{Subtheme 3: Speaking Arabic in Public or Identifying as Arab}

Three of the nine participants mentioned experiencing being treated or looked at differently because of their ethnicity and four of the nine participants experienced it because they spoke Arabic in public. For example, many non-Muslims do not think Sara is of Arab descent and when she corrects them, she said, "that's when the whole thing starts. I get that a lot when they find out that I'm Arabic." She also discussed an incident where she received a phone call during a cab ride and the driver asked her, "what language was that?" and when she told him Arabic, his response was "oh so you're one of them?" A similar experience at the grocery store was revealed by Miriam, where she was talking on the phone and a woman walked up to her and told her, "you're in America, speak English" and walked away.

Kamal also described similar experiences stating that when "you start speaking a different language they look at you like you're going to do something or starting to do something or trying to do something." Musa shared similar experiences at the airport stating, "they see you speaking Arabic basically they search you a lot longer and start asking you more questions than they would ask other people." Participants also revealed experiencing being treated or looked at differently because they were of Arab descent. For example, Mona stated, "people look at you differently because of where you're from" and Abed also recalled, "I went to a store and just the fact that I was Arabic and Muslim, the cashier told me that 'I don't serve your kind of people."

\section{Theme 3: Prejudice and Discrimination "Everywhere" and "Anywhere"}

Four out of the 10 participants specifically mentioned experiencing prejudice and discrimination from nonMuslims "everywhere" and "anywhere," while another four specified having these experiences in different locations. When Mona was asked where she experienced prejudice and discrimination the most, she responded by saying, "honestly, anywhere you go nowadays. It doesn't matter where you are, whether you're at school, whether you're at work, whether you're in the grocery store." Similarly, Miriam responded with, "it's normal now, you want the truth, it's normal. This is not the first, it's probably not going to be the last; it's anywhere, there isn't one setting."

Dena also answered with a similar response saying, "honestly, it happens all over. It doesn't have a specific area; as soon as they see I wear a hijab there's usually somebody that has to say something smart.” Likewise, Abed also described experiencing prejudice and discrimination "everywhere, everywhere, everywhere. I've experienced it everywhere." The following subtheme emerged during the analysis of the participants' discussions about experiencing prejudice and discrimination at specific locations.

\section{Subtheme 1: Specified Locations}

As mentioned in the previous section, four participants also described experiencing prejudice and discrimination by non-Muslims. For instance, Musa said, "[it] happens at work a lot, the airport is one, in a more affluent neighborhood, restaurants." Such incidences were also described by Sara ("at the dentist office, at the gym, it's where I'm at. That's where they see me") and Hasan ("I've seen it in schools, with schools the most; kids bullying other kids. Out in the public, even being at the barber shop"). Finally, Kamal mentioned 
that he "usually saw it when I was up north in the country like [in] Maine the community is mainly White and when they see somebody that is not White."

\section{Theme 4: Emotional Distress}

Eight of the participants reported experiencing emotional distress when asked how the experiences they had with non-Muslims made them feel. Sara described the incident with the cab driver as, "it made me feel unsafe. It hurt me. It made me sick." Also, during her account of an incident with a woman who asked her about Jesus then verbally attacked her, Sara stated, "I was actually just stunned, confused. I didn't know how to react. I didn't know what to feel."

Expressing a similar reaction regarding an incident of a man throwing things and shouting profanities at her, Dena described, “I didn’t know what I did wrong, and I just went home. That traumatized me to this day.” She further discussed that,

I'm traumatized. I had to take off my hijab the next day. I honestly was too scared to even walk home by myself. I quit cosmetology, until this day honestly, I just don't walk by myself anymore. I just don't leave anywhere as much as long as it's with my husband.

Furthermore, Miriam's response was, “my hijab does not in any way say who I am as a person. It's normal now. You anticipate it at this point, to be honest." Likewise, during her account of the incident at the grocery store with her mother, Mona recalled feeling "angry, I was upset, I was very surprised more than anything."

There were also male participants expressing emotional distress from their interactions with non-Muslims. For example, Hasan said he felt, "uncomfortable, looked at different or didn't belong here, didn't feel wanted" whenever he prayed in public; and Musa stated feeling, "violated. Violated, not trusted, ashamed to be an American" when he has negative interactions with non-Muslims. Similarly, Kamal expressed that he felt "sad and to be honest like ashamed because the people that treat you that way are also minority just like me." Abed revealed that the incident at the cafe "led to an altercation" and that he "really got offended" during the incident with the cashier who did not want to serve him. However, it also made him "feel really bad" and "really sad" because "we're all the same, we all bleed the same color. It doesn't have to be that way."

\section{Theme 5: Avoiding or Ignoring Non-Muslims}

In order to not experience negative interactions with non-Muslims, three of the participants mentioned avoiding or ignoring them. Musa, for instance, stated that although he felt "violated" from his negative experiences with non-Muslims, "honestly, I really don't take it to heart. I'm the type of person that I try not to let it bother me." Similarly, Ahmad said, "I never took it personal. For me, it was just always "kill them with kindness." Dena also expressed similar views, especially after the incident she described about a man throwing things at her while she walked home from school stating, "I just ignore them. I just move along with the day. I just try not to get involved with them."

\section{Theme 6: Tolerance Among Muslims and Non-Muslims is "Good and Bad" or "It Depends"}

Of the 10 participants in the study, four felt that tolerance among Muslims and non-Muslims was "good and bad" or "it depends." Miriam described the tolerance as,

it depends on the situation. There are times where we could be somewhere and meet someone and just strikes up a conversation with me, it's pretty cool. Then you can go somewhere, and you can feel it's an 
uncomfortable situation; not every situation is the same and not every area that you happen to be is the same.

Dena believes “it's not that bad, it depends on where you live too.” Kamal responded saying, "It's been good and bad; me being as a Palestinian, a lot of Americans know the struggle we've been through, and they stand by us and some of them it's bad, depending on how you look at it." Finally, Mona expressed a similar response stating,

You have some people out there that are amazing, they just come up to you and have a normal conversation and treat you as if you're not any different and you have the ones that just automatically see a Palestinian or whatever it is and just automatically drive by you and flip you off or try to harass you for it.

\section{Theme 7: "Us vs. Them" or "We vs. They"}

Four participants expressed their views using terms likes "us vs. them" or "we vs. they" when asked how they felt about the tolerance among Muslims and non-Muslims, such as Sara, who said,

Muslims tolerate a lot. We're more passive when it comes to this kind of things. We don't blame anybody for us. We just think that they're less educated when it comes to us. We don't get mad about it. The other part, on the other hand, they get angry because they think that we are the ones who are closed-minded but the matter of fact is because they're not taking the time to educate themselves and some of them don't want to educate themselves. It might be because they just don't want to or they're just too lazy to learn about other religion[s]. I think they don't tolerate us because of them.

Similarly, Musa expressed his response by stating, "I think Muslims have more patience because of their faith, but that can be challenged sometimes. I just think we have more patience.” Hasan expressed a similar description responding with,

Non-Muslims, some of them look at us differently. I feel like some of them try taking things out on you and try to feel you out. Seeing if you really are religious or if you are not. They'll ask questions or try to influence you into things you shouldn't. I think people try to test you.

Finally, Fatima responded by saying, "if it's very clear they're Muslim, people don't hold back. It's like they have no fear of being rude or hurting somebody's feelings or it's like you have no guilty conscience, it's really sad."

\section{Discussion}

The results of this study support the argument presented by Simon et al. (2017) that there is a need to understand the point of view of minorities regarding the level of intolerance displayed by majority members, as well as understand how the social experiences of Muslim Americans can influence their emotions, intentions, and behavior towards non-Muslims. Some participants in the present study described avoiding situations that they perceived to have similar negative outcomes based on their social and emotional experiences, a social process that Ajzen's (1991) described in the theory of planned behavior. In this process, intentions and behavior are influenced by the emotions and social pressures individuals experience. Other participants in this study described how their physical appearance can be mistaken for other than Middle Eastern, which allows them to avoid the intolerance displayed by non-Muslims. According to Goffman's impression management theory, self-representation is used as a way of avoiding undesirable social experiences by attempting to control the impression of others (Goffman, 1959, as cited in Paliszkiewicz \& Madra-Sawicka, 2016). 
Participants in the current study described experiencing emotional distress as a result of observing the experiences of others or personally experiencing the intolerance displayed by non-Muslims, which involved being physically or verbally attacked. As a result of the emotional distress experienced by the participants, some reported changing their daily routines and social behavior as a way of attempting to avoid similar negative situations and outcomes. Dena described no longer walking home from school alone after being verbally attacked and having objects thrown at her. This example supported Ajzen's (1991) theory of planned behavior in that the emotional and social experiences of the participants regarding the intolerance displayed by non-Muslims had a significant influence on their perception and behavior towards non-Muslims. The emotional distress experienced by the participants in this study also influenced the way they perceived themselves as "we" and non-Muslims as "them," reinforcing the perception of ingroup and outgroup social boundaries that limit the interactions and exchange of new information among Muslims and non-Muslims.

The findings from this research also supported those described in previous literature regarding the generalizations and stereotypes experienced by Muslims; in which participants reported observing or experiencing the intolerance by non-Muslims in airports, school, cafés, parks, and grocery stores. Some female participants in the study reported that they felt this was motivated by the hijab they wear that socially represents their religious and cultural beliefs. Most participants could not clearly say why they thought this happened but suggested that it was probably motivated by the negative representations of Muslims by media outlets and the lack of education among non-Muslims regarding the religion of Islam and Middle Eastern culture. Kamal reinforced this argument and the importance of creating situations that allow for the exchange of new information among Muslims and non-Muslims. When describing his relationship with his neighbors, he stated,

If you have a neighbor that's non-Muslim and he knows you personally, he knows what kind of character you are and how you practice your religion; they know what the religion is as a whole. They cannot pinpoint "just because this person did this, everybody in the religion or the religion as a whole are bad."

The findings of this study demonstrated the importance and need for understanding of the functions and consequences of the intolerance displayed by majority members through newly discovered information not found in recent literature. The findings also reinforced the need for minority members to develop strategies for social interactions among Muslims and non-Muslims in the United States.

\section{Limitations of the Study}

Limitations in this study included that the social experiences explored were limited to Palestinian Muslim Americans who resided in Cleveland, Ohio, and do not represent the social experiences of Palestinian Muslim Americans in other states. I explored the social experiences of Palestinian Muslim adults over the age of 18 and did not explore those under the age of 18 who may have different social experiences than the adults interviewed for this study. A phenomenological design was used for this study, which asked participants to recall their lived experiences regarding the phenomena being explored. As a result, the responses of the participants are dependent on their ability to accurately recall previously experienced events. Important factors involving the events described by the participants may not have been recalled. There may also have been possible unintentional bias based on the emotions of the participants regarding the event being described.

Although face-to-face interviews have advantages, using this data collection method has a few limitations. The information obtained from face-to-face interviews came directly from the participants; however, the information was filtered through the participants' point of views which may be indirectly altered. Also, I did not directly observe the situations or events shared by the participants. Finally, it was assumed the participants were truthful and provided accurate details of their experiences. 
Abderrazzaq, 2021

\section{Recommendations}

Further research on the social experiences of other Muslim Americans who are of a different ethnicity or located in other states or cities within the United States is needed. Such research can be helpful in creating a broader understanding or identifying other social variables that may have not been identified in this study. Also, exploring the social experiences of Muslim Americans under the age of 18 may reveal new information not found in this study, considering their daily routines and activities may be different from the adults interviewed in this study. Expanding on this study by exploring the social experiences of other Muslim Americans in the United States may help in the development of social strategies that can be used to improve the social interactions among Muslims and non-Muslims in the United States.

Encouraging and motivating engagement and communication among Muslims and non-Muslims in the United States can help strengthen the cohesion and resilience among community members of different religious and ethnic backgrounds. Developing and promoting social strategies that influence the interactions among community members of different religious and cultural backgrounds can allow for the discovery of new information among members regarding similar interests and concerns within the community. Social strategies such as community events that recognize cultural differences such as arts, foods, customs, and promote diversity can motivate and create new social interactions among individuals and groups of different cultural and religious backgrounds. This can allow for the discovery of new information among community members. Through the sharing of new information among community members, ingroup and outgroup members may begin to perceive themselves differently based on their shared concerns and interests within the community. Recategorizing outgroup and ingroup members to an inclusive shared identity (community member) can help increase prosocial behaviors and reduce intergroup bias (McDowell-Smith, 2013).

Social strategies such as community events developed by community leaders or public officials can allow new experiences to be discovered among ingroup and outgroup members, which can help to build trust among members of different religious and cultural backgrounds. Developing social/economic conditions and programs that increase civic engagement and strengthen ties are needed in strengthening the social cohesion among members of different cultural and religious backgrounds in the United States (Ellis \& Abdi, 2017). Implementing the social strategies suggested in this study regarding cultural and social events that allow for the exchange and sharing of new information, interests, and concerns among community members of different cultural and religious backgrounds can help to promote positive social change among Muslims and non-Muslims, while also contributing to the overall safety and well-being of community members. 


\section{References}

Ajzen, I. (1991). The theory of planned behavior. Organizational Behavior and Human Decision Processes, 5o(2), 179-211. https://doi.org/10.1016/0749-5978(91)90020-T

Ajzen, I., \& Fishbein, M. (2000). Attitudes and the attitude-behavior relation: Reasoned and automatic processes. European Review of Social Psychology, 11(1), 1-33.

https://doi.org/10.1080/14792779943000116

Alase, A. (2017). The interpretative phenomenological analysis (IPA): A guide to a good qualitative research approach. International Journal of Education \& Literacy Studies, 5(2), 9-19. https://doi.org/10.7575/aiac.ijels.v.5n.2p.9

Ali, S. R., Yamada, T., \& Mahmood, A. (2015). Relationships of the practice of hijab, workplace discrimination, social class, job stress, and job satisfaction among Muslim American women. Journal of Employment Counseling, 52(4), 146-154. https://doi.org/10.1002/joec.12020

Amer, M. M., \& Bagasra, A. (2013). Psychological research with Muslim Americans in the age of Islamophobia: Trends, challenges, and recommendations. American Psychologist, 68(3), 134-144. https://doi.org/10.1037/a0032167

American Psychological Association. (2003). Guidelines on multicultural education, training, research, practice, and organizational change for psychologists. American Psychologist, 58, 377-402. doi: 10.1037/0003-066X.58.5.377

American Psychological Association. (n.d.). Experience. In APA dictionary of psychology. https://dictionary.apa.org/experience

Boddy, C. R. (2016). Sample size for qualitative research. Qualitative Market Research: An International Journal, 19(4), 426-432. https://doi.org/10.1108/QMR-06-2016-0053

Brooks, J., McCluskey, S., Turley, E., \& King, N. (2015). The utility of template analysis in qualitative psychology research. Qualitative Research in Psychology, 12, 202-222. https://doi.org/10.1080/14780887.2014.955224

Creswell, J. W., \& Creswell, J. D. (2018). Research design: Qualitative, quantitative, and mixed methods approaches (5th ed.). Sage Publications.

Dictionary.com. (n.d.). Intolerance. https://www.dictionary.com/browse/intolerance

Ellis, B. H., \& Abdi, S. (2017). Building community resilience to violent extremism through genuine partnerships. American Psychologist, 72(3), 289-300. https://doi.org/10.1037/ampooooo65

Giorgi, A. (2012). The descriptive phenomenological psychological method. Journal of Phenomenological Psychology, 43, 3-12. https://doi.org/10.1163/156916212X632934

Giorgi, A., Giorgi, B., \& Morley, J. (2017). The descriptive phenomenological psychological method. In C. Willig, \& W. Stainton-Rogers (Eds.), The SAGE handbook of qualitative research in psychology (2nd ed., pp. 176-192). Sage Publications.

Jackson, C., Vaughan, D. R., \& Brown, L. (2018). Discovering lived experiences through descriptive phenomenology. International Journal of Contemporary Hospitality Management, 30(11), 33093325. https://doi.org/10.1108/IJCHM-10-2017-0707

Khan, S. R. (2014). Post 9/11: The impact of stigma for Muslim Americans. Peace and Conflict: Journal of Peace Psychology, 20(4), 580-582. https://doi.org/10.1037/paco0o0063

Kishi, K. (2017, November 15). Assaults against Muslims in the U.S. surpass 2001 level. http://www.pewresearch.org/fact-tank/2017/11/15/assaults-against-muslims-in-u-s-surpass-2001-level/ 
Lamont, S., \& Collet, B. (2013). Muslim American university students' perceptions of Islam and democracy: Deconstructing dichotomy. Equity \& Excellence in Education, 46(4), 433-450. https://doi.org/10.1080/10665684.2013.838126

Leary, M. R., \& Kowalski, R. M. (1990). Impression management: A literature review and two-component model. Psychology Bulletin, 107(1), 34-47. https://doi.org/10.1037/0033-2909.107.1.34

Matua, G. A., \& Van Der Wal, D. M. (2015). Differentiating between descriptive and interpretive phenomenological research approaches. Nurse Researcher, 22(6), 22-27. https://doi.org/10.7748/nr.22.6.22.e1344

McDowell-Smith, A. (2013). Can the heuristic model of positive terror management enhance prosocial values and reduce intergroup conflict? The case of Muslims in the USA. International Journal of Teaching and Case Studies, 4(4), 367-382. https://doi.org/10.1504/IJTCS.2013.060643

Mohamed, B. (2018, January 3). New estimates show U.S. Muslim population continues to grow. http://www.pewresearch.org/fact-tank/2018/01/o3/new-estimates-show-u-s-muslim-populationcontinues-to-grow/

Mohibullah, H., \& Kramer, C. (2016). "Being true to ourselves...within the context of Islam”: Practical considerations in hijab practice among Muslim American Women. Practical Matters Journal, 2016(9), 102-117. http://practicalmattersjournal.org/wpcontent/uploads/2016/04/Mohibullah_and_-Kramer_Being-True-to-Ourselves.pdf

Paliszkiewicz, J., \& Mądra-Sawicka, M. (2016). Impression management in social media: The example of LinkedIn. Management, 11(3), 203-212. http://www.fm-kp.si/zalozba/ISSN/1854-4231/11_203-212.pdf

Rosenthal, L., Levy, S. R., Katser, M., \& Bazile, C. (2015). Polyculturalism and attitudes toward Muslim Americans. Peace and Conflict: Journal of Peace Psychology, 21(4), 535-545. https://doi.org/10.1037/pacoooo133

Saleem, M., Prot, S., Anderson, C. A., \& Lemieux, A. F. (2017). Exposure to Muslims in media and support for public policies harming Muslims. Communication Research, 44(6), 841-869. https://doi.org/10.1177/0093650215619214

Samari, G. (2016). Islamophobia and public health in the United States. American Journal of Public Health, 106(11), 1920-1925. https://doi.org/10.2105/AJPH.2016.303374

Selod, S. (2014). Citizenship denied: The racialization of Muslim American men and women post-9/11. Critical Sociology, 41(1), 1-19. https://doi.org/10.1177/0896920513516022

Simon, B., Eschert, S., Schaefer, C. D., Reininger, K. M., Zitzmann, S., \& Smith, H. J. (2018). Disapproved, but tolerated: The role of respect in outgroup tolerance. Personality and Social Psychology Bulletin, 110. https://doi.org/10.1177/0146167218787810

Terry, G., Hayfield, N., Clarke, V., \& Braun, V. (2017). Thematic analysis. In C. Willig, \& W. Stainton-Rogers (Eds.), The SAGE handbook of qualitative research in psychology (2nd ed., pp. 17-37). Sage

Tseëlon, E. (1992). Is the presented self sincere? Goffman, impression management and the postmodern self. Theory, Culture \& Society, 9(2), 115-128. https://doi.org/10.1177/026327692009002006

Thompson, R. (2018). A qualitative phenomenological study of emotional and cultural intelligence of international students in the United States of America. Journal of International Student, 8(2), 12201255. https://doi.org/10.5281/zenodo.1250423

Zainiddinov, H. (2016). Racial and ethnic differences in perceptions of discrimination among Muslim Americans. Ethnic and Racial Studies, 39(15), 2701-2721. https://doi.org/10.1080/01419870.2016.1164877 


\section{Appendix A: Interview Question}

1. Tell me about a situation in which you feel that your religious or ethnic background influenced the way you were treated.

- Probe: Tell me how this experience made you feel? (If not directly answered)

2. What is your experience as a Palestinian Muslim American, living in the United States?

- Probe: Could you describe some of the activities you experience throughout your day? (If not directly answered)

3. Tell me about your experience regarding the prejudice and discrimination displayed by non-Muslims.

- Probe: Where have you experienced it the most? (If not directly answered)

- Probe: Why do you think it occurs more in this type of setting? (If not directly answered)

4. Can you tell me how you feel regarding the tolerance among Muslims and non-Muslims in the United States?

5. I appreciate your time and willingness to participate in the interview. Is there anything else that you would like to share with me that you feel is important for me to know?

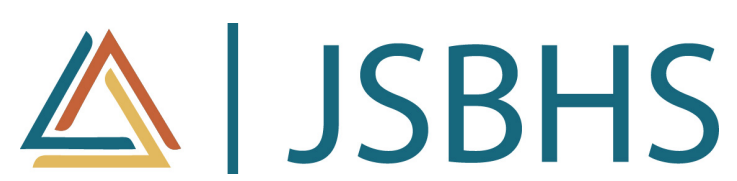

The Journal of Social, Behavioral, and Health Sciences (JSBHS), cosponsored by the College of Health Professionals and the College of Social and Behavioral Sciences at Walden University, is a peer-reviewed, online, interdisciplinary journal focusing on theoretically based research that addresses contemporary national and international issues. JSBHS articles include peer-reviewed research reports, brief reports, comprehensive literature reviews, book reviews, and student research. 